\title{
Response to first dose of inhaled albuterol in mechanically ventilated preterm infants
}

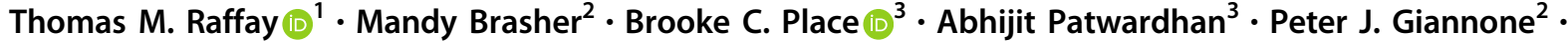 \\ Henrietta Bada ${ }^{2}$ Philip M. Westgate ${ }^{4}$ Elie G. Abu Jawdeh $\oplus^{2}$
}

Received: 21 October 2020 / Revised: 23 March 2021 / Accepted: 26 April 2021 / Published online: 25 May 2021

(c) The Author(s), under exclusive licence to Springer Nature America, Inc. 2021

\begin{abstract}
Background Bronchodilator responses among preterm infants are heterogeneous. Bedside measurements may identify responders.

Study design Respiratory measurements (Resistance, Compliance, $\left.\mathrm{FiO}_{2}\right)$ and pulse oximetry $\left(\mathrm{SpO}_{2}\right)$ patterns were downloaded from infants $<30$ weeks gestational age during the first 2 months of life. Mechanically ventilated infants who received albuterol were included $(n=33)$. Measurements were compared before and after first albuterol. Secondary analyses assessed subsequent doses.

Results Median gestation and birthweight were 25 3/7 weeks and $730 \mathrm{~g}$, respectively. Mean Resistance decreased postalbuterol $(p=0.007)$. Sixty-eight percent of infants were responders based on decreased Resistance. Compliance and $\mathrm{FiO}_{2}$ did not significantly differ. Percent time in hypoxemia $\left(\mathrm{SpO}_{2}<85 \%\right)$ decreased post albuterol $(p<0.02)$. In responders, Resistance changes diminished with subsequent administration (all $p=0.01$ ).

Conclusions Ventilator resistance decreased in two-thirds of preterm infants, consistent with studies that utilized formal pulmonary function testing. Albuterol had a variable effect on delivered $\mathrm{FiO}_{2}$; however, hypoxemia may be useful in evaluating albuterol response.
\end{abstract}

\section{Introduction}

Neonatal respiratory insufficiency necessitating supplemental oxygen and mechanical ventilation is required for most extremely preterm infants cared for in the neonatal intensive care unit (NICU) [1], unfortunately, these interventions may contribute to airway hyper-reactivity and chronic lung disease [2]. Airway smooth muscle is present

Philip M. Westgate

philip.westgate@uky.edu

$\bowtie$ Elie G. Abu Jawdeh

elie.abujawdeh@uky.edu

1 Pediatrics/Neonatology, UH Rainbow Babies and Children's Hospital, Case Western Reserve University, Cleveland, OH, USA

2 Pediatrics/Neonatology, University of Kentucky, Lexington, KY, USA

3 Biomedical Engineering, University of Kentucky, Lexington, KY, USA

4 Biostatistics, University of Kentucky, Lexington, KY, USA in the preterm airways and contains neural elements responsive to cholinergic and other constrictive stimuli [3], which may precipitate airway narrowing, worsen respiratory mechanics, and lead to hypoxemia. The preterm airways also contain $\beta 2$-adrenergic receptors ( $\beta 2$-AR) capable of agonist-stimulated bronchodilation [4]. Preterm infants at high risk for chronic lung disease show evidence of hypertrophy of airway muscle as early as 10 days of age [5]. Therefore, it is not uncommon for NICU clinicians and respiratory therapists to use inhaled $\beta 2$-AR agonists, such as albuterol, to potentially relieve bronchoconstriction and wheezing, decrease airway resistance, and improve oxygenation in preterm infants with evolving and established chronic lung disease [6-10]. While systematic reviews have not shown convincing data of their efficacy in the prevention of chronic lung disease or other long-term morbidities associated with prematurity $[11,12]$, many preterm infants do show improvements in pulmonary function testing following inhaled $\beta 2$-AR agonist therapy [4, 13-16]. Of note, some infants may never be responders in the NICU $[4,16]$ or have the potential to develop tolerance and become nonresponders over time $[13,17]$. 
When individual pulmonary function testing is not available or feasible, clinicians will accordingly use physical exam and fraction of inspired oxygen $\left(\mathrm{FiO}_{2}\right)$ requirements to identify infants likely to benefit from scheduled $\beta 2$-AR agonist therapy. Still, classifying responders remains a challenge without a discrete marker of treatment effect. The current bedside ventilator and monitors may have objective measures to assess $\beta 2$-AR agonist responders such as airway resistance and intermittent hypoxemia. Intermittent hypoxemia ( $\mathrm{IH}$ ), a decrease in oxygenated hemoglobin $\left(\mathrm{SpO}_{2}\right)$, has been shown to correlate with responses to therapeutic blood transfusions [18, 19], and are associated with later diagnoses of chronic lung disease [20, 21], childhood asthma medication use [22], and mortality [23]. Continuous pulse oximetry monitoring provides a noninvasive modality for assessing oxygenation in the neonate and is used extensively in most NICUs [24].

The objective of this study was to utilize available bedside monitoring of intubated preterm infants to report upon respiratory and oxygenation changes (Resistance, Compliance, $\mathrm{FiO}_{2}$, and $\mathrm{SpO}_{2}$ ) following the first dose of albuterol. We hypothesized that ventilator measures of dynamic Resistance will decrease, dynamic Compliance will increase, $\mathrm{FiO}_{2}$ will decrease, and percent time in hypoxemia will decrease after albuterol is administered. As a secondary outcome, we also investigated if changes in Resistance continue with repeated albuterol administration in first-dose responders.

\section{Methods}

This was a secondary analysis of responses to albuterol administration (2 puffs via a $90 \mathrm{mcg}$ metered-dose inhaler (MDI) without an aerochamber spacer) in mechanically ventilated preterm infants from a cohort of infants cared for in the Level IV NICU of University of Kentucky [18, 25]. All infants $<30$ weeks without major congenital anomalies were approached for enrollment after parental consent. Respiratory measures (Resistance, Compliance, and $\mathrm{FiO}_{2}$ ) were prospectively collected from the bedside mechanical ventilator (Draeger Babylog VN500; 4-5 min sampling rate) during the first 2 months of life. Intermittent hypoxemia measures were prospectively collected using highresolution research pulse oximeters (Masimo Radical 7, $1 \mathrm{~s}$ sampling rate, $2 \mathrm{~s}$ averaging time). Baseline characteristics and albuterol administration were retrospectively collected from medical records and matched with cohort participants. Gestational age was based on best obstetrical dating. Small for gestational age was $<10$ th percentile for gestational age by Fenton preterm growth charts. Chorioamnionitis was based on clinical diagnosis by obstetrical provider. Surfactant delivery was through an endotracheal tube. Patent ductus arteriosus diagnosis is based on echocardiogram findings. Institutional review board approval was obtained during the acquisition of the oxygen saturation data with waiver of consent for the current report.

\section{Statistical analyses}

For each subject, Resistance, Compliance, $\mathrm{FiO}_{2}$, and $\mathrm{IH}$ measures were compared utilizing 4 -h averages pre and post the first albuterol administration. To account for statistical correlation arising from these repeated measurements, paired $t$ tests were utilized to test for a mean change in the given outcome type, and corresponding 95\% confidence intervals are provided. Alternatively, due to the occurrence of outliers in the IH data, we present sample medians and interquartile ranges (IQRs) for changes from pre to post, and utilize the signed rank test with the change in IH as the outcome of interest. Pearson's correlations and corresponding tests were used to assess correlations between outcomes and age.

For the secondary analyses, we obtained 4-h dynamic Resistance averages pre and post the first, second, and third albuterol administrations. We utilized the change in the 4-h averages as the outcome of interest in order to account for statistical correlation at any given dose. Due to each subject contributing these measurements at three different doses, a repeated measures linear model with working unstructured covariance structure was utilized to assess and test for differences in mean dose responses.

All tests were two-sided at the 5\% significance level. Analyses were conducted in SAS version 9.4 (SAS Institute, Cary, NC, USA).

\section{Results}

Out of 218 infants screened, a total of 40 infants received albuterol while on mechanical ventilation in the first 2 months of life. Of those, 33 infants had ventilator or $\mathrm{SpO}_{2}$ data pre/post first albuterol dose administration (28 infants had ventilator data and 28 infants had $\mathrm{SpO}_{2}$ data, of these 23 had both). Baseline characteristics and common neonatal morbidities are presented in Table 1 . The median gestational age (GA) was 25 3/7 weeks (IQR 24 2/7-26 5/7), median birth weight was $730 \mathrm{~g}$ (IQR 640 - 893), and $40 \%$ were female. There was no difference in baseline characteristics between responders and non-responders.

\section{Respiratory measures}

Mean respiratory measurements pre and post albuterol administration are presented in Fig. 1. Resistance decreased in $68 \%$ of infants. The mean Resistance post albuterol 
Table 1 Baseline characteristics of cohort, $n=33$.

\begin{tabular}{|c|c|c|c|}
\hline GA at birth (weeks) & 25 3/7 (24 3/7-26 5/7) & $\operatorname{RDS}(\%)$ & $100 \%$ \\
\hline Birthweight (g) & $730(640-893)$ & Surfactant administration & $100 \%$ \\
\hline Day of life at albuterol dose & $32(28-40)$ & Oxygen on day of life $28(\%)$ & $100 \%$ \\
\hline Weight at albuterol dose & $1200(959-1344)$ & Oxygen at 36 weeks PMA (\%) & $91 \%$ \\
\hline SGA $(\%)$ & $18 \%$ & $\operatorname{PEEP}\left(\mathrm{cmH}_{2} \mathrm{O}\right)$ & $8(7-8)$ \\
\hline Sex $(\%$ female $)$ & $40 \%$ & Respiratory rate (bpm) & $25(20-30)$ \\
\hline Ethnicity (\% White) & $97 \%$ & MAP $\left(\mathrm{cmH}_{2} \mathrm{O}\right)$ & $11(10-14)$ \\
\hline Apgar Scores at $5 \mathrm{~min}$ & $6(3-6)$ & Inspiratory Time (seconds) & $0.4(0.35-0.5)$ \\
\hline Chorioamnionitis & $15 \%$ & PIP $\left(\mathrm{cmH}_{2} \mathrm{O}\right)$ & $25(21-30)$ \\
\hline $\mathrm{ROM}(>18 \mathrm{~h})$ & $24 \%$ & $\mathrm{FiO}_{2}$ & $\begin{array}{l}0.44 \\
(0.34-0.65)\end{array}$ \\
\hline Any PDA & $24 \%$ & & \\
\hline Moderate or Large PDA & $12 \%$ & & \\
\hline $\begin{array}{l}\text { Systemic steroids at } \\
\text { albuterol dose }\end{array}$ & $12 \%$ & & \\
\hline Inhaled steroids at albuterol dose & $0 \%$ & & \\
\hline Diuretics at albuterol dose & $48 \%$ & & \\
\hline Caffeine Therapy & $100 \%$ & & \\
\hline
\end{tabular}

significantly decrease $(p=0.007)$ as shown in Fig. 1A. Compliance increased in $64 \%$ of infants. The mean Compliance increased after albuterol but was not statistically significant ( $p=0.29$ ) (Fig. $1 \mathrm{~B}) . \mathrm{FiO}_{2}$ increased post albuterol in $50 \%$ of infants. The overall increase in $\mathrm{FiO}_{2}$ was not statistically significant $(p=0.21)$ (Fig. 1C). There were no statistically significant correlations found between respiratory measures and GA and postnatal age.

\section{Intermittent hypoxemia measures}

Intermittent hypoxemia measures pre and post albuterol administration are presented in Fig. 2. The percent time in hypoxemia (\%time-SpO $\mathrm{Sp}_{2}<80$ and \%time- $\mathrm{SpO}_{2}<85$ ) decreased after albuterol administration in $68 \%$ of patients. Due to outliers, median change was calculated. Both \%time$\mathrm{SpO}_{2}<80$ and \%time-SpO $\mathrm{S}_{2}<85$ decreased after albuterol as presented in Fig. 2 (all $p<0.02$ ). There were no statistically significant correlations found between $\mathrm{IH}$ measures and GA and postnatal age.

\section{Secondary analyses}

Secondary analyses were performed to assess the albuterol responses of subsequent administrations in infants who responded to initial therapy. Of the 19 responders in terms of a decrease in Resistance, 10 infants received additional albuterol doses as prescribed by their primary clinical team. All ten infants received at least three doses. Interestingly, the average response was significantly diminished with the second and third administration when compared to the first dose (all $p=0.01$ ), Fig. 3. Additional doses $(>3)$ were not included in this analysis due to small sample size as the number of infants prescribed albuterol decreased with subsequent doses.

\section{Discussion}

We observed that archived bedside monitoring shows that ventilator measures of Resistance and pulse oximetry measures of $\mathrm{IH}$ decreased after inhaled albuterol in the majority of ventilated preterm infants. Contrary to our original hypothesis, ventilator measures of Compliance and delivered $\mathrm{FiO}_{2}$ did not significantly change. Although measured differently and in controlled settings, our findings of decreased Resistance following inhaled albuterol are congruent with the $\sim 70 \%$ of individual responders reported in other studies [16, 26, 27]. While variable results of average blood oxygenation have been previously reported in multiple albuterol studies [14, 15, 26, 28, 29], we believe we are the first to quantify percent time in hypoxemia parameters (\%time- $\mathrm{SpO}_{2}<80$ and \%time- $\left.\mathrm{SpO}_{2}<85\right)$ in pre- and post-albuterol evaluations utilizing pulse oximeter histogram profiles.

As highlighted by Slaughter et al. in their extensive database review, there is considerable variability amongst US institutions for the indications, timing, use, and type of bronchodilators prescribed for preterm infants in the 
A

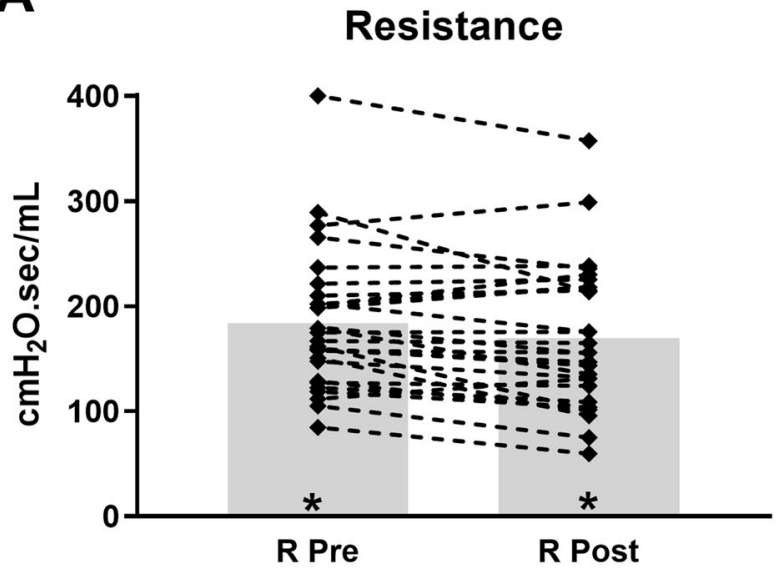

B

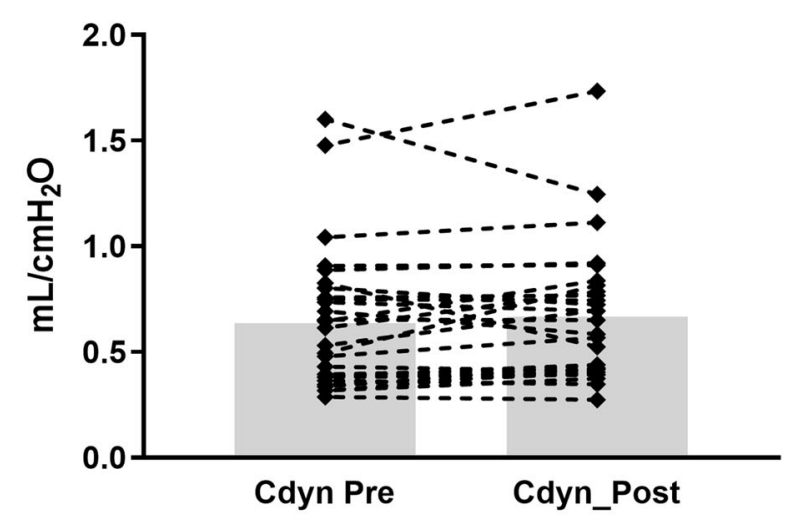

C

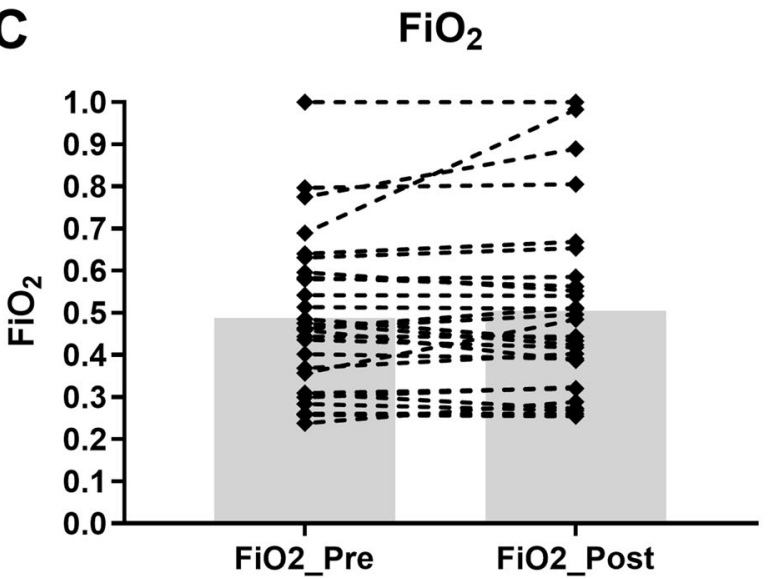

Fig. 1 Resistance decreases after albuterol. Mechanical ventilator measurements of A Resistance (R), B Compliance (Cdyn), and C Fraction of Inspired Oxygen $\left(\mathrm{FiO}_{2}\right) 4 \mathrm{~h}$ before (Pre) and four hours after (Post) albuterol inhalation showed a significant decrease in mean Resistance ( ${ }^{*} p<0.05$, two-tailed paired $t$ test). Significant changes in Compliance and $\mathrm{FiO}_{2}$ were not detected. Individual data points (diamonds) and group means (gray bars) are shown. $n=$ 28 subjects.
A

\section{$\%$ time-SpO $2<80$}

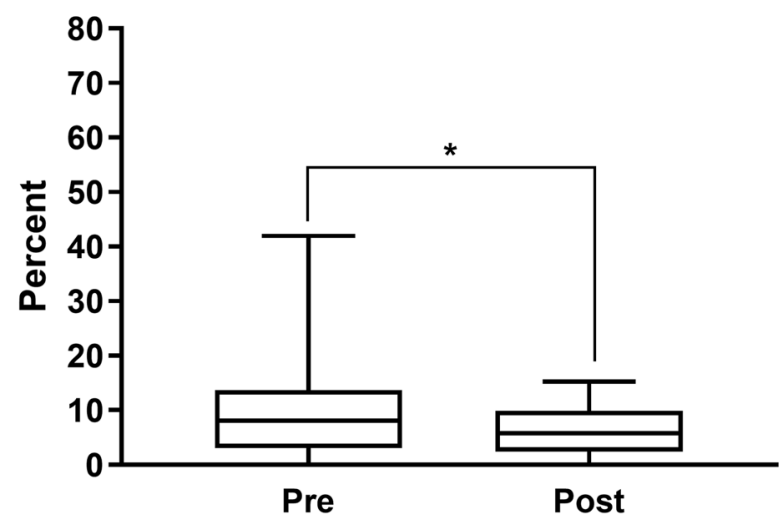

B
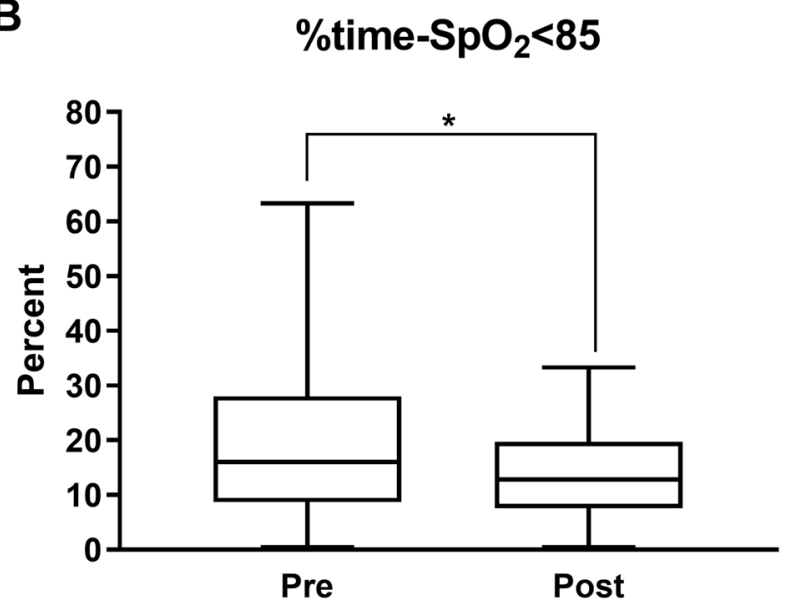

Fig. 2 Intermittent hypoxemia decreases after albuterol. Pulse oximetry histogram profiles of $\mathbf{A}$ percent time spent with $\mathrm{SpO}_{2}<80$ $\left(\%\right.$ time- $\mathrm{SpO}_{2}<80$ ) and $\mathbf{B}$ percent time spent with $\mathrm{SpO}_{2}<85$ (\%time$\left.\mathrm{SpO}_{2}<85\right) 4 \mathrm{~h}$ before (Pre) and $4 \mathrm{~h}$ after (Post) albuterol inhalation showed a significant decrease in time spent hypoxemic $\left({ }^{*} p<0.05\right.$, Signed Rank Test). Median (line) with interquartile (box) and group ranges (bars) are shown. $n=28$ subjects.

NICU [7]. Furthermore, there are no consensus guidelines for starting or stopping these medications with a paucity of data regarding the impact of both positive and negative outcomes with longer-term use [11, 30]. While formal pulmonary function testing (PFT) in the NICU would ideally characterize the extent of neonatal lung disease and also identify $\beta 2$-AR agonist responders and non-responders either by whole body infant PFT [31], breath occlusion PFT analyses of passive flow-volume curves [16], or plethysmography with helium gas dilution [32]; this requires extensive expertise, precision equipment, and in some cases patient sedation. Dynamic lung mechanics derived during spontaneous breathing may underestimate static mechanics but provide real-time analysis which can give information to assess pre/post changes $[33,34]$. We believe this work is a 


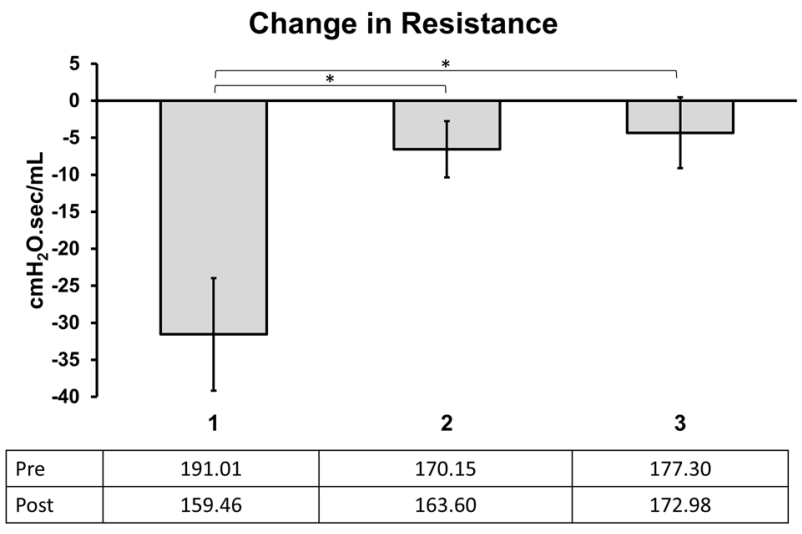

Resistance $\left(\mathrm{cmH}_{2} \mathrm{O} . \mathrm{sec} / \mathrm{mL}\right)$

Fig. 3 Decreases in post-albuterol Resistance changes diminish with second and third dose. Mechanical ventilator measurements of changes in Resistance after albuterol show significantly decreased mean $( \pm$ Std Dev) responses at Dose 2 and Dose 3 compared to Dose 1 $\left({ }^{*} p=0.01\right.$, repeated measures linear model with working unstructured covariance). Raw Resistance measurements $4 \mathrm{~h}$ before (Pre), four hours after (Post) albuterol inhalation of first-time responders are shown. $n=10$ subjects.

step toward early investigation of already available bedside monitoring data which could provide more objective measurements of bronchodilator responses in NICU patients than improved work of breathing, resolution of wheezing, or decrease in $\mathrm{FiO}_{2}$.

Historically, relying upon bedside charting was not ideal [35-38]. However, next-generation mechanical ventilator interfaces and continuous pulse oximetry recordings provide high fidelity measures of respiratory parameters including actual delivered $\mathrm{FiO}_{2}$, desaturation/IH events, and capabilities to profile time spent in hypoxemia. There were improvements in both $\mathrm{IH}$ measures (\%time-SpO $2<80$ and $\%$ time- $\left.\mathrm{SpO}_{2}<85\right)$. A decrease in $\mathrm{IH}$ events is likely an indicator of improved and sustained aeration of previously derecruited airways and alveoli or indicative of elevated $\mathrm{FiO}_{2}$ delivery. Indeed, while not statistically significant the $\mathrm{FiO}_{2}$ increased in half of the study subjects following albuterol. The University of Kentucky NICU uses pulse oximetry targets of $90-95 \%$ and supplemental oxygen is titrated by the bedside nurse or respiratory therapist to maintain target range. It is possible that $\mathrm{IH}$ decreased with higher delivered $\mathrm{FiO}_{2}$ after albuterol, however, $\mathrm{FiO}_{2}$ adjustments in our clinical practice are usually driven by $\mathrm{SpO}_{2}$ changes. This is of potential clinical significance because high-risk patterns of neonatal $\mathrm{IH}$, hypoxemia, and elevated $\mathrm{FiO}_{2}$ have been associated with short and long-term morbidities in preterm infants [39], specifically asthma and chronic lung disease [20-22]. Translational animal studies have shown that superimposed IH may further exacerbate neonatal hyperoxic airway and lung pathology [2].

Previous reports have emphasized improvements in Compliance following albuterol administration [14, 15, 26], whereas, others have reported no significant improvements in Compliance [16, 27, 28]. In this cohort, we did not observe a significant change in Compliance, which may be due to insufficient sample size or the manner in which realtime dynamic Compliance was measured by the mechanical ventilator without utilizing a standard single breath occlusive technique. Alternatively, one may not expect albuterol, as a bronchodilator, to change compliance measurements. That is to say, if airway narrowing was minimally contributing to extensive lobar atelectasis then a significant improvement in Compliance would not be expected after $\beta 2-\mathrm{AR}$ agonist therapy.

As a planned secondary analysis, the effects of serial albuterol doses were investigated in this patient cohort. $\beta 2$ AR tolerance and tachyphylaxis have been well described in the asthma literature [40, 41], but has been underinvestigated in the NICU with only anecdotal descriptions $[13,42]$ and translational findings in newborn animal models [43]. We noted diminished changes in Resistance after the second and third albuterol doses (Fig. 3). Given the small sample size we were unable to perform statistical analyses beyond three consecutive doses. The dampened response may be due to continued bronchodilatory effects of the previous albuterol dose; however post-treatment mean Resistances remained elevated after the second and third doses when compared to the first dose. Importantly, none of the infants in this study were receiving simultaneous inhaled steroids which would align with current asthma recommendations [44]. Sample size precludes speculating on longitudinal efficacy, but given their frequent use in recent cohorts [10] these findings raise concern and further investigations of chronic $\beta 2$-AR agonist therapy in the NICU population are needed. Of note, the University of Kentucky NICU does not have a NICU protocol for albuterol, prescription is at the discretion of the treating clinician.

This study has limitations as it was a single-center, retrospective study of intubated and mechanically ventilated preterm infants. Albuterol delivered by MDI to the inline ventilator inspiratory tubing is standard practice in our NICU for intubated patients, however different modes of delivery may have yielded different effects [27, 28, 45]. The treating clinical teams initially prescribed and decided to continue albuterol, which may predispose to selection bias and/or confounding-by-indication. We utilized respiratory measures (Resistance, Compliance, $\mathrm{FiO}_{2}$ ) obtained from downloadable current generation mechanical ventilators compared to more standard PFT measurements. While passive ventilator measures have been reported previously [28, 46], studies comparing these passive measurements with invasive or whole body PFTs are needed. Although some may consider this a limitation that may underestimate respiratory parameters [34], we wished to focus upon 
objective data that are readily available at the bedside for clinicians before and after albuterol administration. Similarly, we report upon percent time in hypoxemia rather than frequency and severity measures of $\mathrm{IH}$; as percent time in hypoxemia is also readily available with most bedside monitors $\mathrm{SpO}_{2}$ histograms.

The first dose of albuterol significantly decreased Resistance as continuously measured by mechanical ventilators in two-thirds of preterm infants, consistent with other studies that utilized more standard PFT modalities. Similarly, there was an improvement in percent time in hypoxemia after first albuterol dose administration in the majority of patients. However, albuterol had no significant effect on Compliance or $\mathrm{FiO}_{2}$. The current practice of assessing initial albuterol response before scheduling treatment should focus on Resistance in the mechanically ventilated infant; as $\mathrm{FiO}_{2}$ changes may be variable among preterm infants. Histogram $\mathrm{SpO}_{2}$ patterns, routinely provided by the bedside monitors, may also be useful in evaluating albuterol responders especially while infants are on non-invasive respiratory support, and therefore do not have objective ventilator data. Although we found a diminished response with subsequent albuterol doses, the sample size precluded conclusions. Further studies to assess rapidity of $\beta 2$-AR tolerance or tachyphylaxis in preterm infants with lung disease are needed.

Acknowledgements We thank the support and involvement of the research nurses and staff at the University of Kentucky NICU.

Author contributions TMR, MB, PJG, HB, and EGA designed the study. EGA, MB, BCP, and AP developed data collection methods, collected and archived these data. PMW and EGA analyzed the results. TMR, PMW, and EGA wrote the manuscript with all authors contributing to the final edits.

Funding: The study was funded in part by: (1) The Gerber Foundation (EGA, PI) (2) Kentucky Children's Hospital Children's Miracle Network Research Fund (EGA, PI), (3) University of Kentucky's National Center for Advancing Translational Sciences, UL1RR033173. TMR is supported by NIH K08HL133459-04 grant.

\section{Compliance with ethical standards}

Conflict of interest The authors declare that they have no conflict of interest.

Publisher's note Springer Nature remains neutral with regard to jurisdictional claims in published maps and institutional affiliations.

\section{References}

1. Stoll BJ, Hansen NI, Bell EF, Walsh MC, Carlo WA, Shankaran S, et al. Trends in care practices, morbidity, and mortality of extremely preterm neonates, 1993-2012. JAMA. 2015;314:1039-51.
2. Dylag AM, Raffay TM. Rodent models of respiratory control and respiratory system development-Clinical significance. Respir Physiol Neurobiol. 2019;268:103249.

3. Sparrow MP, Lamb JP. Ontogeny of airway smooth muscle: structure, innervation, myogenesis and function in the fetal lung. Respir Physiol Neurobiol. 2003;137:361-72.

4. Kovacs SJ, Fisher JB, Brodsky NL, Hurt H. Use of a beta-agonist in ventilated, very-low-birth-weight babies: a longitudinal evaluation. Dev Pharmacol Thera. 1990;15:61-7.

5. Sward-Comunelli SL, Mabry SM, Truog WE, Thibeault DW. Airway muscle in preterm infants: changes during development. J Pediatr. 1997;130:570-6.

6. Ballard J, Lugo RA, Salyer JW. A survey of albuterol administration practices in intubated patients in the neonatal intensive care unit. Respir Care. 2002;47:31-8.

7. Slaughter JL, Stenger MR, Reagan PB, Jadcherla SR. Inhaled bronchodilator use for infants with bronchopulmonary dysplasia. J Perinatol. 2015;35:61-6.

8. Guaman MC, Gien J, Baker CD, Zhang H, Austin ED, Collaco JM. Point prevalence, clinical characteristics, and treatment variation for infants with severe bronchopulmonary dysplasia. Am J Perinatol. 2015;32:960-7.

9. Ogawa R, Mori R, Sako M, Kageyama M, Tamura M, Namba F. Drug treatment for bronchopulmonary dysplasia in Japan: questionnaire survey. Pediatr Int. 2015;57:189-92.

10. Greenberg JM, Poindexter BB, Shaw PA, Bellamy SL, Keller RL, Moore PE, et al. Respiratory medication use in extremely premature ( $<29$ weeks) infants during initial NICU hospitalization: results from the prematurity and respiratory outcomes program. Pediatr Pulmonol. 2020;55:360-8.

11. Clouse BJ, Jadcherla SR, Slaughter JL. Systematic review of inhaled bronchodilator and corticosteroid therapies in infants with bronchopulmonary dysplasia: implications and future directions. PLoS One. 2016;11:e0148188.

12. $\mathrm{Ng} \mathrm{G}$, da Silva O, Ohlsson A. Bronchodilators for the prevention and treatment of chronic lung disease in preterm infants. Cochrane Database Syst Rev. 2016;12:CD003214.

13. Motoyama EK, Fort MD, Klesh KW, Mutich RL, Guthrie RD. Early onset of airway reactivity in premature infants with bronchopulmonary dysplasia. Am Rev Respir Dis. 1987;136:50-7.

14. Rotschild A, Solimano A, Puterman M, Smyth J, Sharma A, Albersheim S. Increased compliance in response to salbutamol in premature infants with developing bronchopulmonary dysplasia. $\mathbf{J}$ Pediatr. 1989;115:984-91.

15. Pfenninger J, Aebi C. Respiratory response to salbutamol (albuterol) in ventilator-dependent infants with chronic lung disease: pressurized aerosol delivery versus intravenous injection. Intensive Care Med. 1993;19:251-5.

16. Morrow DK, Schilling D, McEvoy CT. Response to bronchodilators in very preterm infants with evolving bronchopulmonary dysplasia. Res Rep Neonatol. 2015;5:113-7.

17. Fakhoury KF, Sellers C, Smith EO, Rama JA, Fan LL. Serial measurements of lung function in a cohort of young children with bronchopulmonary dysplasia. Pediatrics. 2010;125:e1441-1447.

18. Ibonia KT, Bada HS, Westgate PM, Gomez-Pomar E, Bhandary P, Patwardhan A, et al. Blood transfusions in preterm infants: changes on perfusion index and intermittent hypoxemia. Transfusion. 2018; 58:2538-44.

19. Abu Jawdeh EG, Martin RJ, Dick TE, Walsh MC, Di, Fiore JM. The effect of red blood cell transfusion on intermittent hypoxemia in ELBW infants. J Perinatol. 2014;34:921-5.

20. Fairchild KD, Nagraj VP, Sullivan BA, Moorman JR, Lake DE. Oxygen desaturations in the early neonatal period predict development of bronchopulmonary dysplasia. Pediatr Res. 2019;85:987-93.

21. Raffay TM, Dylag AM, Sattar A, Abu Jawdeh EG, Cao S, Pax BM, et al. Neonatal intermittent hypoxemia events are associated with 
diagnosis of bronchopulmonary dysplasia at 36 weeks postmenstrual age. Pediatr Res. 2019;85:318-23.

22. Di Fiore JM, Dylag AM, Honomichl RD, Hibbs AM, Martin RJ, Tatsuoka C, et al. Early inspired oxygen and intermittent hypoxemic events in extremely premature infants are associated with asthma medication use at 2 years of age. J Perinatol. 2019;39:203-11.

23. Poets CF, Roberts RS, Schmidt B, Whyte RK, Asztalos EV, Bader D, et al. Association between intermittent hypoxemia or bradycardia and late death or disability in extremely preterm infants. JAMA. 2015;314:595-603.

24. Vali P, Underwood M, Lakshminrusimha S. Hemoglobin oxygen saturation targets in the neonatal intensive care unit: is there a light at the end of the tunnel? (1). Can J Physiol Pharmacol. 2019;97:174-82.

25. Gomez-Pomar E, Makhoul M, Westgate PM, Ibonia KT, Patwardhan A, Giannone PJ, et al. Relationship between perfusion index and patent ductus arteriosus in preterm infants. Pediatr Res. 2017;81:775-9.

26. Denjean A, Guimaraes H, Migdal M, Miramand JL, Dehan M, Gaultier C. Dose-related bronchodilator response to aerosolized salbutamol (albuterol) in ventilator-dependent premature infants. J Pediatr. 1992;120:974-9.

27. Gappa M, Gartner M, Poets CF, von der Hardt H. Effects of salbutamol delivery from a metered dose inhaler versus jet nebulizer on dynamic lung mechanics in very preterm infants with chronic lung disease. Pediatr Pulmonol. 1997;23:442-8.

28. Fok TF, Lam K, Ng PC, So HK, Cheung KL, Wong W, et al. Randomised crossover trial of salbutamol aerosol delivered by metered dose inhaler, jet nebuliser, and ultrasonic nebuliser in chronic lung disease. Arch Dis Child Fetal Neonatal Ed. 1998;79: F100-104.

29. Mhanna MJ, Patel JS, Patel S, Cohn R. The effects of racemic albuterol versus levalbuterol in very low birth weight infants. Pediatr Pulmonol. 2009;44:778-83.

30. Allen J, Zwerdling R, Ehrenkranz R, Gaultier C, Geggel R, Greenough A, et al. Statement on the care of the child with chronic lung disease of infancy and childhood. Am J Respir Crit Care Med. 2003;168:356-96.

31. Shepherd EG, Clouse BJ, Hasenstab KA, Sitaram S, Malleske DT, Nelin LD, et al. Infant pulmonary function testing and phenotypes in severe bronchopulmonary dysplasia. Pediatrics. 2018;141:e20173350.

32. Yuksel B, Greenough A. Airways resistance and lung volume before and after bronchodilator therapy in symptomatic preterm infants. Respir Med. 1994;88:281-6.
33. Lucangelo U, Bernabe F, Blanch L. Lung mechanics at the bedside: make it simple. Curr Opin Crit Care. 2007;13:64-72.

34. Stahl CA, Moller K, Schumann S, Kuhlen R, Sydow M, Putensen $\mathrm{C}$, et al. Dynamic versus static respiratory mechanics in acute lung injury and acute respiratory distress syndrome. Crit Care Med. 2006;34:2090-8.

35. Abu Jawdeh EG. Intermittent hypoxemia in preterm infants: etiology and clinical relevance. NeoReviews. 2017;18:e637-e646.

36. Zagol K, Lake DE, Vergales B, Moorman ME, Paget-Brown A, Lee $\mathrm{H}$, et al. Anemia, apnea of prematurity, and blood transfusions. J Pediatr. 2012;161:417-21 e411.

37. Brockmann PE, Wiechers C, Pantalitschka T, Diebold J, Vagedes J, Poets CF. Under-recognition of alarms in a neonatal intensive care unit. Arch Dis Child Fetal Neonatal Ed. 2013;98:F524-527.

38. Di Fiore JM, Poets CF, Gauda E, Martin RJ, MacFarlane P. Cardiorespiratory events in preterm infants: etiology and monitoring technologies. J Perinatol. 2016;36:165-71.

39. Di Fiore JM, MacFarlane PM, Martin RJ. Intermittent hypoxemia in preterm infants. Clin Perinatol. 2019;46:553-65.

40. Salpeter SR, Ormiston TM, Salpeter EE. Meta-analysis: respiratory tolerance to regular beta2-agonist use in patients with asthma. Ann Intern Med. 2004;140:802-13.

41. Muneswarao J, Hassali MA, Ibrahim B, Saini B, Ali IAH, Verma AK. It is time to change the way we manage mild asthma: an update in GINA 2019. Respir Res. 2019;20:183.

42. De Boeck K, Smith J, Van Lierde S, Devlieger H. Response to bronchodilators in clinically stable 1 -year-old patients with bronchopulmonary dysplasia. Eur J Pediatr. 1998;157:75-9.

43. Raffay T, Kc P, Reynolds J, Di Fiore J, MacFarlane P, Martin RJ. Repeated beta-adrenergic receptor agonist therapy attenuates the response to rescue bronchodilation in a hyperoxic newborn mouse model. Neonatology. 2014;106:126-32.

44. Reddel HK, FitzGerald JM, Bateman ED, Bacharier LB, Becker A, Brusselle G, et al. GINA 2019: a fundamental change in asthma management: treatment of asthma with short-acting bronchodilators alone is no longer recommended for adults and adolescents. Eur Respir J. 2019;53:1901046.

45. Khalaf MN, Hurley JF, Bhandari V. A prospective controlled trial of albuterol aerosol delivered via metered-dose inhaler-spacer device (MDI) versus jet nebulizer in ventilated preterm neonates. Am J Perinatol. 2001;18:169-74.

46. Fayon M, Tayara N, Germain C, Choukroun ML, De La Roque ED, Chene G, et al. Efficacy and tolerance of high-dose inhaled ipratropium bromide vs. terbutaline in intubated premature human neonates. Neonatology. 2007;91:167-73. 